\title{
GIS based probabilistic method in sinkhole susceptibility hazard zones
}

\author{
Mohd Asri Hakim Mohd Rosdi, Ainon Nisa Othman, Zulkiflee Abd Latif, Zaharah Mohd Yusoff \\ Applied Remote Sensing \& Geospatial Research Group, Faculty of Architecture, Planning \& Surveying, \\ Universiti Teknologi MARA, Malaysia
}

\begin{tabular}{l} 
Article Info \\
\hline Article history: \\
Received Mar 1, 2019 \\
Revised Jun 28, 2019 \\
Accepted Jul 22, 2019 \\
\hline
\end{tabular}

Keywords:

GIS

Hazard

MCDM

Probabilistic method

Sinkholes

\begin{abstract}
In this era of globalization, natural phenomena often invade the human population. Natural phenomena such as sinkholes often occur in countries whose topology lies in active limestone areas. Malaysia is one of the countries with active limestone areas, especially in the Klang Valley and its surrounding areas. Since 1968, the increase in sinkhole cases in Malaysia has been reported frequently. This has caused many building infrastructures to be destroyed, loss of life and destruction of property. So, one of the steps to overcome this problem is to do an in-depth study of the sinkhole. Therefore, Sinkhole Hazard Model (SHM) has been created with a combination of GIS integration by using probability techniques. There are five criteria suitable for Malaysian topography namely Lithology (LT), Soil Types (ST), Landuse (LU), Groundwater Level Decline (GLD) and Proximity to Groundwater Wells (PGW). Based on probability calculations, GLD and LU have shown a high impact on sinkhole formation. A hazard zonation map has been produced where it has been classified into five parts namely none, low, medium, high and very high. The results were validated with previous inventory data comprising 33 data. Based on the results obtained, 36.37\% and $39.39 \%$ of the sinkhole formation has fallen into high and very high areas respectively. Based on these final results, the integration between GIS and probability techniques is useful in natural phenomena such as sinkhole formation.
\end{abstract}

Copyright $@ 2019$ Institute of Advanced Engineering and Science. All rights reserved.

\section{Corresponding Author:}

Ainon Nisa Othman,

Applied Remote Sensing \& Geospatial Research Group,

Faculty of Architecture, Planning \& Surveying,

Universiti Teknologi MARA, 40450 Shah Alam, Selangor, Malaysia.

Email: ainisa78@gmail.com

\section{INTRODUCTION}

Natural phenomena often occur and are reported either on television or in newspapers especially in Malaysia. This natural phenomenon can occur either naturally or because of human development activities that are too rapid. Each country has its own unique phenomenon. Like Malaysia itself, frequent natural phenomena like floods, landslides, strong winds and sinkhole is the famous phenomenon occurred. This should be taken seriously because this phenomenon of nature can take up to dozens of human lives. According to [1] study, Pinellas County located in Florida USA is the most active area of limestone formation in the world. Therefore, at Pinellas County sinkhole disaster is easily to attack them. Other than that, Italy country also is one of the active sinkhole development.

Many Italian territory are influenced by these catastrophic events. Some of them are brought about by karst breakdown or human-centered movement [2]. Malaysia is also an active state of limestone formation. This causes natural phenomenon such as sinkhole to occur in Malaysia especially in the Klang Valley and surrounding areas. Based on the study of [3], sinkhole can be defined as stresses on the ground 
surface caused by disintegration of the limestone close to the surface or the fall of an underground cave. In Italy the term of sinkhole is utilized to demonstrate a sub circular cavity that opens all of a sudden superficially and is utilized as an equivalent word of crumple [4]. Additionally, sinkhole is developed by progressive failure in which the part of soil nearest to a slot ravels or is eroded, exposing a new soil surface which become unstable in time [5] and depression or shaft formed at a soil surface due to changes in the soil or rock beneath [6]. Sinkholes growing today are commonly the impacts of descending development of mantling sediment into the major karren shafts which drain the epikarstic zone further into the true karstic aquifer [7].

According to [8] study, there are consists of two main genetic groups of sinkholes can be found in karst regions which are an arrangement sinkhole made by the differential dissolutional bringing down of the surface and another one is sinkholes resulting from internal disintegration and deformational processes cause by subsurface karstification of carbonates or evaporites. In Kuala Lumpur there are two types of geological formation in the synthesis of sinkhole namely Kenny Hill Formation where the formation of this type contains sedimentary rock while the second is Kuala Lumpur Limestone Formation where it is popular with highly erratic karstic constituents [9]. According to published geological maps of Kuala Lumpur, it shows that Kuala Lumpur Limestone Formation monopolize the majority of the Malaysian centre city. KLCC and Bukit Bintang is located on Kenny Hill Formation where this formation is one of the dangerous types because it consists of sedimentary rock where the sinkhole is easily to occurred especially with the water presence [9].

There are many sinkhole cases reported in Malaysia since 1968 [10]. The latest sinkhole case occurred in September 2018 which had claimed two teenage boys through the sinkhole at Jalan Taman Serdang about $10 \mathrm{pm}$. The probability of sinkhole presence was not expected by the two adolescents that the road they had passed had collapsed. Fire and Rescue Department and ambulance were present at the scene to divert the victim and both bodies were taken to the hospital for interrogation [11]. Therefore, in addressing this issue, an in-depth study should be made so that it can be avoided and can provide a precautionary measure if the sinkhole builds up. According to a study conducted by [12], sinkhole formation is easy to occur in areas with limestone. There are many factors of sinkholes developments such as urban improvement, faults circulation and ex-mining lakes [13].

Additionally, man-induced sinkholes are related with the expanding industrialization and urbanization of urban areas and the exceptional economic activity in the speculation of the corresponding hydrological frameworks [14]. Civil and industrial engineering on karsted terrain is unsafe [15]. Therefore, any development should take a serious look at the selection of project land to be developed because the sinkhole attack can lead to negative effects such as loss of life, emotional instability, destruction of property and building and lastly reduce the country's economy. Thus, one of the steps that can be taken to address this sinkhole problem is to conduct a drastic and in-depth study. Therefore, GIS and analysis techniques can be applied in anticipation of this sinkhole phenomenon. Some suitable data for Malaysian country has been taken to carry out detailed analysis such as lithology (LT), soil types (ST), landuse (LU), groundwater level decline (GLD) and proximity to groundwater wells (PGW). Lithology is the physical character of a stone or deposit communicated as far as texture, mineralogy, shading and thickness [16].

The probability technique is also applied in this study where the combination of these techniques with GIS can get better results and can be understood easily. The probabilistic technique is an integral tool in handling numerous issues in discrete arithmetic [17]. In other word, probabilistic technique is endeavoring to demonstrate that a structure with certain ideal properties exists, one characterizes an appropriate probability space of structures and afterward demonstrates that the ideal properties hold in this structure and after that demonstrates that the ideal properties hold in this space with positive likelihood [18]. There are three kinds of probabilistic namely relative frequency method is, equal probability method and subjective guess method. In this probabilistic technique, the method that is used is frequency ratio. Frequency ratio method is one of the methods that are widely used in many studies [19].

According to [20] study, frequency ratio method is a measurable way to deal with recreation natural conditions. Other than that, based on [21] study, the frequency ratio approach is based on the observed relationships between the distribution of landslides and each landslide conditioning factor. By using this landslide concept study by [21], sinkhole frequency ratio in this study is utilized by changed it into relationships between the distribution of sinkholes and each sinkhole conditioning factor. This frequency ratio model was utilized in order to demonstrate the distinction quantitatively [22]. Hence, the combination of GIS and probability environments is a very useful and important combination in producing the best results to overcome this sinkhole phenomenon. The objectives of this paper are to developed model of sinkhole using integration of GIS and statistical method and to produce sinkhole susceptibility hazard zone map of the study area.

Indonesian J Elec Eng \& Comp Sci, Vol. 16, No. 3, December 2019：1539 - 1546 


\section{MATERIALS AND METHOD}

There are four main phases to be described to produce a sinkhole susceptibility map namely project planning (phase 1), data acquisition (phase 2), data storage (phase 3) as well as data analysis (phase 4) (Figure 1). These four phases are interlinked to achieve the objectives of the study. In phase 1, there are four main components to be run, namely preliminary study, selection of software used, selection of study area and criteria determination. While in phase 2 it is divided into two ways of obtaining data which is primary data and secondary data. Next, in phase 3 the probability processes will be carried out in sequence to produce a sinkhole susceptibility hazard zone map. Finally, in phase 4, a sinkhole map will be carried out an analysis showing the areas at risk of sinkhole.

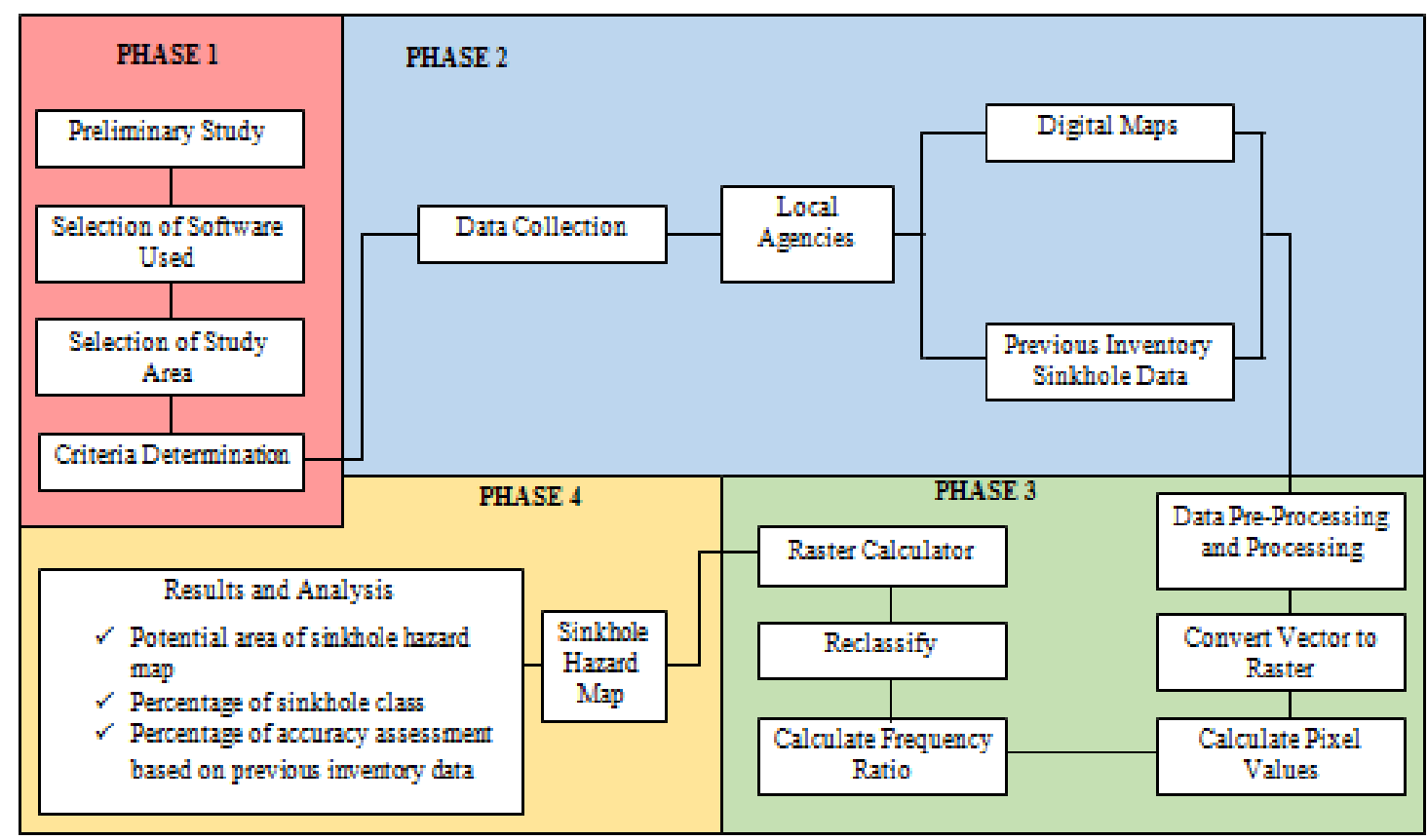

Figure 1. Research Methodology Framework

\section{RESEARCH AREA}

The research area selected to study the presence of the sinkhole is Kuala Lumpur and Ampang Jaya. The total area of Kuala Lumpur is approximately about 279,327 hectares while for Ampang Jaya is approximately about 14,350 hectares. Sinkholes normally have a higher probability of event and a more noteworthy diversity assorted variety in evaporite territories than in carbonate karst zones [23]. Thus, this area is chosen because of the occurrence of this sinkhole phenomenon and also because the location of this area is located within the limestone area. Additionally, accessibility of past sinkhole occurrence data and access information associated with it is also another factor in the selection of study areas. Figure 2 demonstrate the limitation area of the sinkhole territory in this study. 


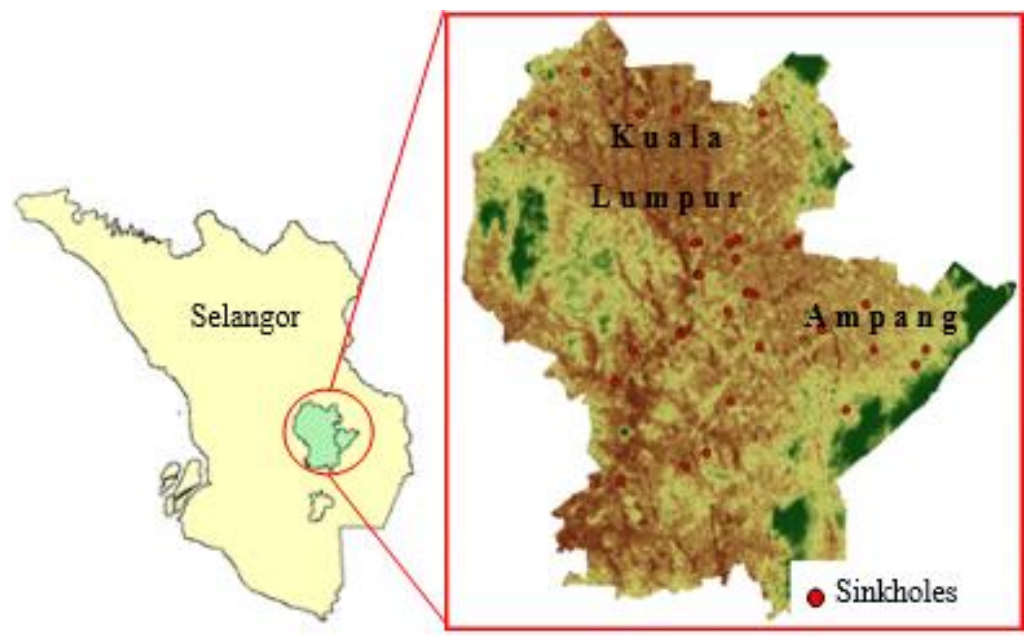

Figure 2. Location of Study Area

\section{DATA COLLECTION}

In this phase, the data collected are based on the five chosen criteria. The criteria selected in this study are based on previous books, journals, articles and papers. The criteria chosen depend on the suitability of a country's landform and the convenience of collecting the data. Therefore, there are five criteria chosen for the study area, namely Lithology (LT), Soil Types (ST), Land Use (LU), Groundwater Level Decline (GLD) and Proximity to Groundwater Wells (PGW). Table 1 demonstrate the sinkhole criteria used and it unit in this study.

Table 1. Sinkhole Used and Unit

\begin{tabular}{cc}
\hline Criteria & Unit \\
\hline Lithology (LT) & Type \\
Soil Types (ST) & Type \\
Landuse (LU) & Type \\
Groundwater Level Decline (GLD) & Meter cubed $\left(\mathrm{m}^{3}\right)$ \\
Proximity to Groundwater Wells (PGW) & Meter $(\mathrm{m})$ \\
\hline
\end{tabular}

Data acquisition in this study was taken from government agencies involved in Malaysia. Among the data taken for the study are digital maps as well as previous sinkhole inventory data. Both data are interlinked to achieve the objectives of the study. Raster data as well as acquired vector data will be collected and will be processed several pre-processing steps that will be described in the next sub-section. Lithology information are obtained from Department of Geoscience and Mineral where it arranged into five developments which is schist development, rock development, hawthornden development, Kenny Hill arrangement and Kuala Lumpur limestone arrangement. The soil types information has been recovered from Department of Agriculture where this information comprises of five kinds of soil to be specific namely alluvium, clay loam, sand, sandy clay and steepland. In the meantime, landuse maps additionally got from a similar division were utilized to separate sort of land use in Kuala Lumpur and Ampang. Five landuse classifications is recognized which is cleared land, forest, grasses, mined land and urban land. For water level decline information and proximity groundwater wells, they can be recovered from Department of Irrigation and Drainage where this information gives the water level data began from - 1 until - 70 and area of the wells individually. A past sinkhole record is recovered from Department of Geoscience and Mineral where it comprises of 33 sinkhole inventory information. This inventory information is utilized as information validation where it demonstrates the past sinkhole area at the Kuala Lumpur and Ampang Jaya.

\section{DATA PROCESSING}

In probabilistic procedure, there are a few stages so as to create the sinkhole susceptibility risk zones map. The most urgent steps in this procedure are the spatial features should in raster data or in pixel so as to create the sinkhole susceptibility risk zone map. There are two spatial data in this study should be changed 
over into raster which are feature data for each criterion utilized and another is sinkhole inventory feature. In this way, the conversion preparing is the initial steps before continue to the others probabilistic method. This change will give the information in pixel format where each pixel of the feature comprises their very own pixel value. Hence, the conversion tool in ArcGIS is utilized to change over the vector information into raster information. This tool will calculate the raster value for every pixel by utilizing cell centre.

The estimation of frequency ratio (FR) is the subsequent stage for the probabilistic method. In this progression, the total pixel value of main criteria of each class has been determined before changed it into percentage. The accompanying equation is utilized so as to compute the FR value:

$$
\mathrm{FR}=\frac{\text { Percentage pixel values of sinkholes occurrence }}{\text { Percentage pixel values for each criteria }}
$$

FR value with less than $1(<1)$ contribute most reduced probability of sinkhole event while FR value with more than $1(>1)$ contribute most elevated probabilistic of sinkhole event [24, 25]. In view of the outcome, the most elevated total FR value is 4.74 and 3.12 for groundwater level decline and land use individually. This FR value should be included attribute table for each instigating criterion as another table. Next, reclassifying is done so as to create sinkhole susceptibility risk zone. Reclassify is one of the tools utilized in this study where it changes the raster value. This tool has an accuracy control that administers how decimal spots are managed. Consequently, the FR value must be assign as 100 during this processing because the new values just can be perused as a whole number so as to continue the following stage. Old values that have a similar number will be join and perused as one attribute table.

Lastly, raster calculator tools have been utilized so as to create the sinkhole susceptibility hazard zone. This preparing is finished by summation all the reclassify layer of each inducing variable into one equation.

\section{RESULT AND ANALYSIS}

Sinkhole susceptibility hazard zone maps information have been ordered into five classes in particular namely none (class 1), low (class 2), medium (class 3), high (class 4) and very high (class 5) where it comprises $21.20 \%, 23.93 \%, 19.09 \%, 23.39 \%$ and $12.39 \%$ of the study area separately. From the result, it found that the most elevated commitment of sinkhole event on North West of Peninsular Malaysia. This happened because of the region of this event is situated on limestone formation topography that comprising of acid intrusive and limestone where these two components fasten the sinkhole development to happened. There are three kinds of sub-criteria give the most noteworthy commitment of sinkhole development which are groundwater level declined, land use and alluvium. The most elevated range of GLD that gives more prominent effect of sinkhole is - 45 to - 31 cubic meters. Besides, the urban land is another inducing subcriterion that gives the most elevated commitment of sinkhole development. The sprawl of commercial and residential building in this study area was erected on the ex-mined land which comprise of sands and clay properties. Figure 3 demonstrates that last result after a few handling process is carried out.

In order to solid the last output, accuracy assessment is one of the procedures can be utilized. In this research it was assessed by overlaying with past inventory sinkholes information that recovered from The Malaysian Mineral and Geoscience Department where it comprises of thirty-three (33) area purpose of past sinkhole that generally happened encompass Kuala Lumpur and Ampang Jaya. There are two huge classes that incorporated into this study namely high and very high in order to approve the technique used. In view of the outcome, there are comprises of 25 past sinkholes area has been situated on high and very high classes for probabilistic technique. Table 2 demonstrates the percentage of accuracy assessment using probabilistic method. In view of the table, the accuracy is validated about $75.76 \%$ is situated within high and very high classes in order to foresee the potential sinkhole hazard area of the investigation territory.

Table 2. Accuracy Assessment of Probabilistic Method

\begin{tabular}{ccccc}
\hline Class & Area $\left(\mathrm{km}^{2}\right)$ & Area Percentage $(\%)$ & Number of Sinkhole & Sinkhole Percentage $(\%)$ \\
\hline None & 56.125 & 21.202 & 0 & 0 \\
Low & 63.358 & 23.933 & 2 & 6.06 \\
Medium & 50.537 & 19.091 & 6 & 18.18 \\
igh & 61.910 & 23.387 & 12 & 36.37 \\
Very High & 32.791 & 12.387 & 13 & 39.39 \\
Total & 264.721 & 100 & 33 & 100 \\
\hline
\end{tabular}




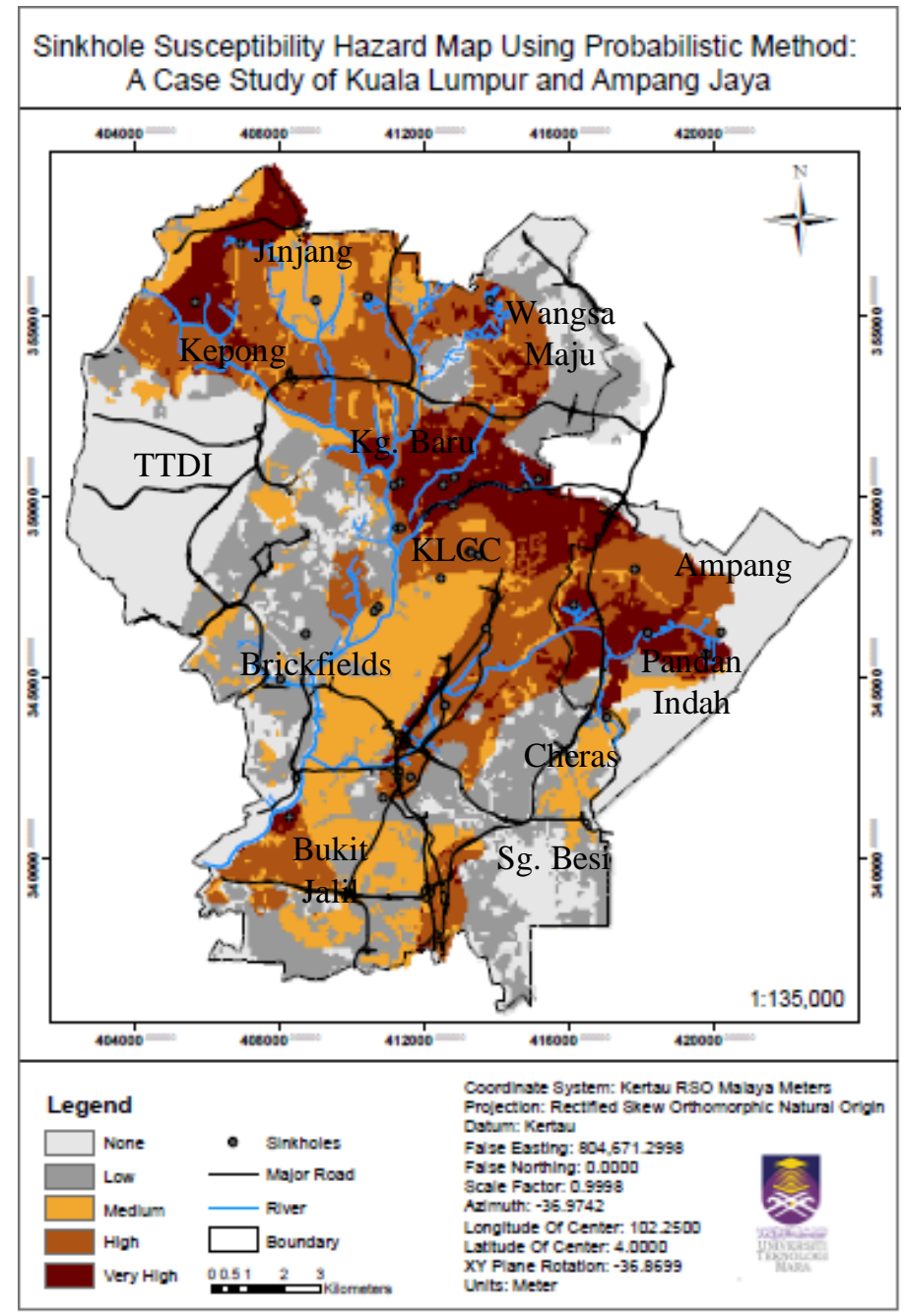

Figure 3. Sinkhole Susceptibility Hazard Zone Map

\section{CONCLUSION}

The sinkhole phenomenon is not a new phenomenon of nature. This phenomenon has long been occurred but the formation of this phenomenon takes time to produce. This phenomenon often attacks a country with a rapid and active limestone area. Since 1968, this phenomenon has been reported rising in Malaysia especially in the Klang Valley and surrounded territory. The impact of these catastrophic causes leads to negative effects such as destruction of property, loss of life, economic degradation and emotional disturbance of society. In this study, five major criteria were selected for their suitability and data acquisition in Malaysia namely lithology (LT), soil types (ST), landuse (LU), groundwater level decline (GLD) and proximity to groundwater wells (PGW). Through these criteria, a technique has been conducted which is the probability technique for submitting some specific analysis of sinkhole attacks in this country. Through this technique, a sinkhole susceptibility hazard zone map has been created to show the area the probability of occurring this phenomenon that combined with the previous sinkhole inventory data. Therefore, the integration of GIS and also this probability technique is able to help solve the problem of this sinkhole phenomenon. Through the final decision of this study, it can be used by government companies or privacy in carrying out infrastructure development activities in the country.

\section{ACKNOWLEDGEMENT}

Special thanks to Kementerian Pengajian Tinggi Malaysia (KPT) for the monetary fund under the research grant (FRGS/1/2016/WAB05/UITM/02/7), Dewan Bandaraya Kuala Lumpur (DBKL) and Department of Mineral and Geoscience for the data and expert opinion. 


\section{REFERENCES}

[1] R. Brinkmann, et al., "Sinkhole distribution based on pre-development mapping in urbanized Pinellas County, Florida, USA," Natural and Anthropogenic Hazard in Karst Area: Recognition, Anaylsis and Mitigation, pp. 5-11, 2007.

[2] S. Nisio, et al., "Sinkhole in Italy: First Results on the Inventory and Analysis," Natural and Anthropogenic Hazards in Karst Areas: Recognition, Analysis and Mitigation. Geological Society of London, Special Publication, pp. 23-45, 2007.

[3] T. S. Meng, "Karstic Features of Kuala Lumpur Limestone," Geological Society of Malaysia, Bulletin, vol. 46, pp. 447-453, 2005.

[4] J. Malczewski, "GIS and Multicriteria Decision Analysis," New York, John Wiley \& Sons, 1999.

[5] Y. C. Chan, "Factors Affecting Sinkhole Formation," Geotechnical Engineering Office, Civel Engineering Department Hong Kong, Geo Report No. 281988.

[6] C. E. Augarde, et al., "Prediction of Undrained Sinkhole Collapase," Journal of Geotechnical and Geoenvironmental Engineering, pp. 1090-0241, 2014.

[7] B. F. Beck, "Environmental and Engineering Effects of Sinkholes - the Process Behind the Problems," International Assciation of Hydrogeologists in Guilin, China. Environmental Geology Water Science, vol. 12, pp. 71-78, 1988

[8] J. P. Galve, et al., "Probabilistic sinkhole modelling for hazard assessment," Earth Surface Processes and Landforms 34, John Wiley \& Sons, Ltd, pp. 437-452, 2009.

[9] M. A. H. M. Rosdi, et al., "Sinkhole Susceptibility Hazard Zones Using GIS Framework and Heuristic Method," Advances in Remote Sensing and Geo Informatics Applications. Advances in Science, Technology \& Innovation (IEREK Interdisciplinary Series for Sustainable Development). Springer, Cham, pp. 261-264, 2019.

[10] M. A. H. M. Rosdi, et al., "Sinkhole Susceptibility Hazard Zones Using GIS and Analytical Hierarchical Process (AHP): A Case Study of Kuala Lumpur and Ampang Jaya," The International Archives of the Photogrammetry, Remote Sensing and Spatial Information Sciences, GGT Kuala Lumpur Malaysia, vol. XLII, 2017.

[11] NST Online, "Two Teenagers Buried Alive After Falling into Sinkhole," 2018. Available: https://www.youtube.com/watch?v=d_NzUJVuzbl.

[12] R. Z. Abidin, et al., "Sinkhole Physical Properties and Its Failure Risk Assessment. Shah Alam, Selangor," Institute of Research, Development And Commercialisation UiTM, 2002.

[13] O. A. Kouri, et al., "Geospatial Modeling for Sinkhole Hazard Map Based on GIS \& RS Data," Journal of Geographic Information System, pp. 584-592, 2013.

[14] T. Toulkeridis, et al., "Causes and consequences of the sinkhole at El Trebol of Quito, Ecuador - Implications for economic damage and risk assessment," Nat. Hazards Earth Syst. Science, pp. 2031-2041, 2016.

[15] Baryakh A. A. and Fedoseev A. K., "Sinkhole Formation Mechanism," Journal of Mining Science, Institute of Mining, Siberian Branch, Russian Academy of Science, vol 47, pp. 12-22, 2011.

[16] W. J. Stone, "Hydrogeology in Practice: A Guide to Characterizing Ground-Water Systems," Prentice Hall, Upper Saddle River, NJ. 1-7, pp. 37-109, 1999.

[17] N. Alon and J. H. Spencer, "The Probabilistic Method," John Wiley \& Sons, Inc, Second Edition, 2000.

[18] N. Alon and J. H, Spencer, "The Probabilistic Method," John Wiley \& Sons, Inc, Third Edition, 2008.

[19] A. Ozdemir, "Sinkhole Susceptibility Mapping Using a Frequency Ratio Method and GIS Technology Near Karapinar, Konya-Turkey," Procedia Earth and Planetary Science, vol. 15, pp. 502-506, 2012.

[20] M. Javad, et al., "Using Frequency Ratio for Spatial Landslide Prediction," Research Journal of Applied Science, Engineering and Technology, vol. 7, pp. 3174-3180, 2014.

[21] L. T. Tay, et al., "Landslide Hazard Mapping of Penang Island, Malaysia,” ID: 314, 2014.

[22] S. I. Elmahdy and M. M. Modamed, "Probabilistic frequency ratio model for groundwater potential mapping in AL Jaww plain, UAE," Arabian Journal of Geoscience, 2014.

[23] F. Gutierrez, et al., "Identification, prediction and mitigation of sinkhole hazards in evaporite karst areas," Environmental Geology. Springer-Verlag, 2007.

[24] B. Pradhan and S. Lee, "Delineation of landslide hazard areas on Penang Island, Malaysia, by using frequency ratio, logistic regression, and artificial nueeural network models," Environment Earth Science. Springer, pp. 10371054, 2009.

[25] J. C. Kim, et al., "Groundwater productivity potential mapping using frequency ratio and evidential belief function and artificial neural network models: focus on topographic factors," Journal of Hydroinformatics, 2018.

\section{BIOGRAPHIES OF AUTHORS}

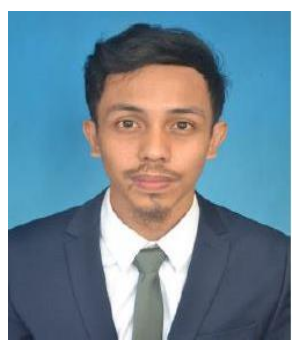

Mohd Asri Hakim Mohd Rosdi is current a Masters student at the Faculty of Architecture, Planning \& Surveying, Universiti Teknologi MARA, 40450 Shah Alam, Selangor, Malaysia. 

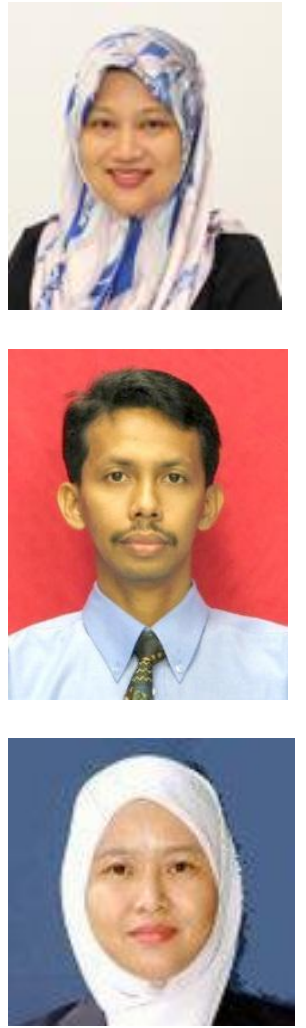

Sr. Dr. Ainon Nisa binti Othman is currently a senior lecturer at Faculty of Architecture, Planning \& Surveying, Universiti Teknologi MARA, 40450 Shah Alam, Selangor, Malaysia. Experienced in GIS and remote sensing working environment and related to disasters management.

Professor Sr Dr. Zulkiflee Abd Latif has more than 20 years of teaching, research and industrial experience (KLCCB) and has published over 90 research articles in refereed journals and conferences. Dr Zulkiflee specializes in Geomatics, Remote sensing, GIS and soft computing techniques in forestry, natural hazard, health and environmental problems. He is currently Head of Applied Remote Sensing \& Geospatial Research Group, UiTM and a Fellow to Royal Institute of Surveyors, Malaysia (RISM).

Dr. Zaharah Mohd Yusoff is currently a senior lecturer at Faculty of Architecture, Planning \& Surveying, Universiti Teknologi MARA, 40450 Shah Alam, Selangor, Malaysia. Her interest is focused around housing, transportation and related studies that combine both areas such as crime with physical and environmental influences, law and regulations of housing and transportation and issues of humanity, safety,live ability and affordability. 